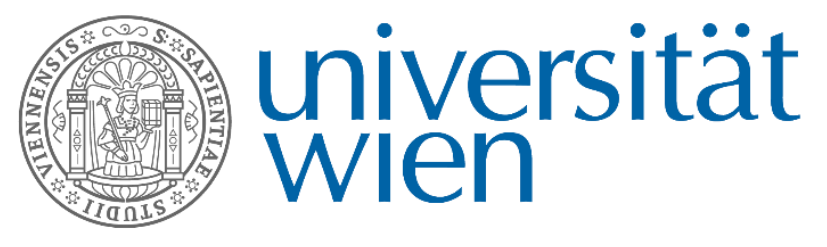

\title{
A view of what pandemic itself tells us in terms of climate change and what it made complex
}

\author{
Bekir S. Öndin
}

Department of Communication Science, University of Vienna 
Sooner after the pandemic was declared and nowadays, some scientists, researchers and media have tended to associate Covid 19 with the results of climate change and give insights about how it needs to be interpreted in an economic, social, political, communicational dimensions for combat against climate change, as well as what has been learnt/can be learnt from it, and what else can be carried out by being followed what has been learnt, etc.. The essay relies on a view of what we learnt from the pandemic on the matter of climate change, and whether some approaches might be derived from what we experienced and learnt from the pandemic, and, most importantly, those would be applicable to combating the climate change as well as the current approaches related to the subject.

At the first glance, taking account into the importance of comparison for theoretical development in anthropology and the relevance of contemporary history for anthropological research on globalization, the connection between Covid 19 and climate change might be established by addressing the issue from the spectrum of globalization.

Within the globalization period, on the one hand, policymakers acknowledged the truth with a global consensus that climate change resulted from human activity, on another hand, the same policymakers tend to pursue a policy aiming at economical growth which is underpinned by fossil fuels and other non-renewable resources (Eriksen, 2016). As a result of accelerated growth perceived as the contemporary world, contact and isolation, as Covid 19 has shown, are difficult due to developments in communication and transportation which get the growing global population ever closer together (Eriksen, 2016).

A study found an association between long term exposure to air pollution and higher COVID-19 mortality rates (Bernstein, 2020). ${ }^{3}$ Pointing out that "many of the root causes of climate change also increase the risk of pandemics", Dr. Aaron Bernstein, Director of Harvard Chan C-Change, points out, additionally, that deforestation taking place because of human activity for agricultural purposes plays a key role in habitat loss globally and that "forces animals to migrate, contact other animals or people and share germs" (Eriksen, 2016).

Considering that the world is interconnected where rights, duties, opportunities, and constraints have been long unevenly distributed and capitalism holds contradictions and unsteadiness ${ }^{5}$, this situation can be predicted that much more pandemics would occur along with the growth of the global population unless the adaptation and mitigation process are taken seriously. Similar to 
climate change, COVID-19 affected vulnerable people, Black, Indigenous, and people of color, and made racial health inequities evident according to the U.S. Policy Brief (Renee, 2020).

The conclusion to be drawn from this is that while dealing with the global effects of global events, the local consequences should not be excluded. This globally interconnected contains chronic crises which are ungovernable, volatile and replete with unintended consequences and this causes an unstable relationship between universalizing and localizing processes (Eriksen, 2016). When we outline this looking at the overheating perspective, the local area should be addressed primarily and global processes as being inherently contradictory (Eriksen, 2016). As an example, humanity in a sense has been experiencing the rehearsal of more destructive demolitions which emerge from climate change. Some infectious diseases occurring in particular local areas did not get as much attention as Covid 19 did, and local disasters and consequences resulting from climate change are not put on the agenda on a global spectrum.

Nowadays, a call for interdisciplinary collaboration to find adaptational solutions to climate change might have increased with Covid 19. Transdisciplinary literature regards integration from actors/stakeholders and scientists affected by environmental issues as a regulative ideal for producing normative knowledge and policy-relevant solutions (Hadorn et al., 2006; Lang et al., 2012), however, some researchers criticized that setting the integration as a regulative can obscure "the friction, antagonism, and power inherent in knowledge co-production". By doing so, "innovative and experimental ways of understanding and adapting to climate change" will be excluded (Castree et al., 2014).

On the other hand, it might be said that together with science, politic, media and the public regarding Covid 19 and the measures against it, they have performed remarkable cooperation in interdisciplinary knowledge co-production and social learning on climate change. This collaboration can be interpreted that it is promising for climate change, as people comprehended the spectrum of the upcoming disaster.

For example, the Nieman Journalism Lab refers to the importance of interdisciplinary collaboration in this period;

"News organizations around the world have learned important lessons from covering Covid-19 that could become valuable for how they cover the climate crisis. The degree of interdisciplinary 
collaboration with the science desk is new, and it could prove a model for how news organizations cover the climate crisis. Today, news reports about the climate crisis primarily come from a newsroom's science, politics or economics desk."

In general, some spheres are sceptical about whether Covid 19 would enable interdisciplinary collaboration on climate change or even block it. But the thing to remember here is that "effective adaptation to climate change requires informed policy making, which in turn will require research paradigms to evolve toward an integration of natural and social science approaches and local knowledge (Ayre and Nettle, 2015; Lynch et al., 2008)."

Having concern that political decision will play determining role in recovering economies shaken after Covid, Lukas H. Meyer and Marcelo de Araujo; state that it might imply that some states would previously reject agreed-upon international climate change targets. Thus, it can be interpreted as that in transdisciplinary cooperation, political decisions may dominate with another crisis, therefore, other actors' decisions may be excluded in transdisiplanary cooperation.

Generally saying, as the Covid experiences demonstrate, the issues of representation and inequality come to the fore. The Triangulation approach, which has been proposed as an alternative, seems to be a more accurate approach since it centres on these problems and sets democratic representation conditions.

Another factor that I think will play a key role in the transfer of knowledge about climate change in such an environment is climate change education, or climate change environmental education. It ensures a variety of interdisciplinary learning opportunities for individuals to enhance their competencies, dispositions and knowledge in terms of tackling climate change (APA, 2013).

Although there is a wealth of information and a high level of issue awareness, the level of action needed to mitigate climate risks to humans and the natural system has remained still low. Some societies put other issues like water supply, pollution, health care as well as the economy first than climate change concerns. Climate change concern has, however, increased significantly since 2015 (Saad, 2016). However, this promising progress can sometimes lead to blurring the range of opinions at a local level and the fact that climate change is a highly politicized issue in many countries. 
Some literature found some correlation between making climate change personally relevant and meaningful, and increasing climate science understanding, shifting climate change attitudes, and inspiring action (Monroe et al). Similarly, while some environmental psychologists have already started including communications strategies around the pandemic, which might give climate activists and educators an opportunity, climate psychologist Beth Karlin gives some successful examples that people have kept up with some new terminologies like "flattening the curve" and "social distancing. She also assesses the media strategies regarding the pandemic as creative solutions for psychologists to adopt and adds they can convey hard scientific facts through those strategies (DeAngelis 2020).

Moreover, as Karlin says "the social, physical and emotional changes wrought by COVID-19 present opportunities to change any number of sustainability behaviors, including travel, transit, shopping, energy choices, volunteer habits and more" (DeAngelis 2020), this momentum can be adapted into the climate crisis communication to alter people behaviors over climate educators.

Another fact is that Covid 19 allows people to change their communication agenda. A survey, 2020, conducted by Yale and George Mason universities indicates that "78 per cent of US adults want more news about climate impacts in their local area. Equally wide majorities want more news about how local, national, and foreign governments are tackling the climate crisis" (McCormick, 2021).

Framing climate change with positive, solutions-based messaging by highlighting public health can be an effective method. As some research revealed that the health frames resulted in the most hope than national security and risks to the environment, some people from different groups, conservatives, and independents, were more likely to engage in climate change mitigation if it is a matter of public health (Myers et al). This implication is especially important to underpin the argument that the pandemic can facilitate the communication of climate change. These findings suggest that some segments of the public may find health a more approachable, tangible subject than climate science, thus eliciting more hopeful feelings and inspiring climate action.

The source from which information about climate change is disseminated, and therefore trust, is also important (Ariel Malka). According to findings of the 2021 Reuters Digital News report on the general view of the media in the Covid 19 period trust in the news has grown worldwide, on 
average by six percentage points, bringing levels of trust back to those of 2018. This brings us to think about whether climate change can be conveyed through messages created from Covid 19.

The another point is the icon employed in visual communication strategies to evoke concern in people and to catch attention to climate change. As it is known from the literature, "Climate change is a notoriously difficult issue to communicate because it is scientifically complex, not easily graspable and deals with vast timespans that lie mostly in the future but are connected to the past (Doyle, 2009).”

Assuming that a campaign would be prepared to draw attention to climate change by creating an icon, for instance, a bat, over the pandemic. I am not talking about a message blaming the bats, of course, but rather the message that bats migrate to different regions as a result of climate change and the virus is formed as a result of contact with other micro-organisms there. The increasing interest of the people due to corona can be transferred to the climate issue through the campaignsupported icon. The main theme of the study can be to provide perspectives on the issue of climate change over the pandemic and how it can contribute to studies on climate change, if so.

Assuming that this would emerge as a result of a common agreement based on similar causes and scientific outcomes, it is necessary to look at what they are, which can also be read as subtexts of the icon.

Some researchers have already started examining the origins of COVID and found that other factors may be in play. As mentioned above, recent research revealed that "people who live in places with poor air quality are more likely to die from COVID-19" (Bernstein, 2020). Additionally, addressing climate change can help prevent pandemics. For instance, deforestation is seen to be one of the main causes for both cases. Deforestation by itself results in between 10 and 20 per cent of carbon pollution. Dr. Aaron Bernstein added "we also know that deforestation contributes to the spillover of pathogens from animals to people" (Bernstein, 2020).

To add dimension to the subject by looking again at the academic debates on creating an icon through the polar bear, On the one hand, some researchers tackle the icon suspiciously as it may miss out on the human aspects regarding the issue (Dunaway, 2009) (Stenport \& Vachula, 2017), but Swim and Bloodhart (2015) argue that the polar bear icon might lead to climate change 
awareness. Additionally, some pay attention to the potential of visualizations to help communicate climate change and to evoke a more tangible idea of this abstract issue (O'Neill \& Nicholson-Cole, 2009) by establishing a more personal connection with climate change (Lorenzoni, NicholsonCole, \& Whitmarsh, 2007).

However, it is criticized to blur the causes of climate change in a wide spectrum and therefore its effectiveness has been questioned (Mooallem, 2013). "At the time the COVID-19 outbreak was declared a global pandemic, climate change was at the forefront of political conversations and agendas" (Moore, 2021). On the one hand, this can also be read as an advantage for climate change by making a connection. On the other hand, it can be read as putting the climate issue into the background.

By creating an ikon through the pandemic, the theme might not be seen as an abstract and temporally remote issue of climate change, as people have still been experiencing the effect of the pandemic everywhere. Similarly, Slocum (2004) argues that the icon facilitates localizing of climate change as a global issue. He add also "it allows visualizing its effects and consequences. Thus, the icon fosters identification with an endangered species, provides "public proof" for climate change and allows raising awareness for this timely matter."

As a conclusion, a broader and more diverse visual icon, which would include the causes and complexities of climate change as well as the contingency of these conditions, could open up debates and foster imaginations of change.

Considering that both the Pandemic and climate change have added and will add new ones to many existing socio-economic inequalities, the imperial mode of living, which has been seen by some as an exemplary lifestyle in combating climate change and the social dimension of climate change, became even more important in terms of making the reproduced and obscured unsustainable social relations visible. However, It should be considered that IML poses ambiguity that it present the opportunity of wealth for not for the whole humanity but just privileged part of humanity. The sustainability and basis of the IML rely on the idea that the external sphere is material, and environmental destruction and the exploitation of labor power (Brand et.al, 2018).

In addition to that, although the pandemic has made social inequalities more evident and the overall climate discourse or policy maker's focus seems optimistic on climate issues, but these 
developments are not in the direction of eradicating social inequalities. Addressing the social and ecological inequalities and calls in this direction in order to draw lessons from the pandemic is essential for making future projections.

As a conclusion, after seeing the magnitude of the harm of Covid 19 toward health, economies and social well-being and social and ecological inequalities coming out through Covid 19, it is not sensible to support a new life format created by the capitalist system as a solution for climate change.

\section{Bibliography}

Aaron Bernstein MD, MPH, A. B. (n.d.). Coronavirus and Air Pollution. Harvard T.H. Chan School of Public Health. https://www.hsph.harvard.edu/c-change/subtopics/coronavirus-and-pollution/

Aaron Bernstein MD, MPH, A. B., \& Renee N. Salas MD, MPH, MS, R. N. S. (n.d.). Coronavirus and Climate Change. Harvard T.H. Chan School of Public Health.

https://www.hsph.harvard.edu/c-change/subtopics/coronavirus-and-climate-change/

Andrew McCormick, A. M. C. (2021). The most important climate summit in history is a local news story, too. Columbia Journalism Review. https://www.cjr.org/covering_climate_now/cop 26-climate-change-local-news.php

American Association of Environmental Education, 2013, http://www.eecapacity.net. Lydia Saad and Jeffrey M. Jones, "U.S. Concern about Global Warming at an Eight-Year High," Gallup.com, March 16, 2016

Ariel Malka, Jon A. Krosnick, and Gary Langer, "The Association of Knowledge with Concern about Global Warming: Trusted Information Sources Shape Public Thinking," Risk Analysis 29, no. 5 (May 2009): 633-47; Andrew J. Hoffman, How Culture Shapes the Climate Change Debate (Stanford, CA: Stanford University Press, 2015).

Ayre, M., Nettle, R., 2015. Doing integration in catchment management research: insights into a dynamic learning process. Environ. Sci. Policy 47, 18-31.

Brand, Ulrich, and Markus Wissen. "What kind of great transformation? The imperial mode of living as a major obstacle to sustainability politics." GAIA-Ecological Perspectives for Science and Society 27.3 (2018): 287-292.

Castree, N., Adams, W.A., Barry, J., Brockington, D., Bu“ scher, B., Corbera, E., Demeritt, D., Duffy, R., Felt, U., Neves, K., Newell, P., Pellizzoni, L., Rigby, K., Robbins, P., Robin, L., Rose, 
D.B., Ross, A., Scholsberg, D., So“ rlin, S., West, P., Whitehead, M., Wynne, B., 2014. Changing the intellectual climate. Nat. Clim. Change 4, 763-768.

Digital News Report 2021. (2021). Reuters Institute. https://reutersinstitute.politics.ox.ac.uk/digital-news-report/2021

Doyle, J. (2009). Seeing the climate? The problematic status of visual evidence in climate change campaigning. In S. I. Dobrin \& S. Morey (Eds.), Ecosee: Image, rhetoric, nature (pp. 279-298). Albany, NY: SUNY Press.

Dr. Aaron Bernstein, A. B. (2020). What combating climate change can teach us about fighting COVID-19. UNICEF. https://www.unicef.org/globalinsight/stories/what-combating-climate change-can-teach-us-about-fighting-covid-19

Dunaway, F. (2009). Seeing global warming: Contemporary art and the fate of the planet. Environmental History, 14(1), 9-31.

Eriksen, Thomas Hylland. "Overheating: the world since 1991." History and anthropology 27.5 (2016): 469-487. https://doi.org/10.1080/02757206.2016.1218865

Hadorn, G.H., Pohl, C., Bammer, G., 2006. Solving problems through transdisciplinary research. In: Klein, J.T., Carl, M. (Eds.), The Handbook of Interdisciplinarity. OUP, Oxford, pp. 431-452.

Laura Downey et al., eds., "Advancing Climate Change Environmental Education:

Resources and Suggestions," EE Capacity, Cornell University, Civic Ecology Lab, North

Lorenzoni, I., Nicholson-Cole, S., \& Whitmarsh, L. (2007). Barriers perceived to engaging with climate change among the UK public and their policy implications. Global Environmental Change, 17(3), 445-459. doi:10.1016/j.gloenvcha.2007.01.004

Lukas H. Meyer, L. H. M., \& Marcelo De Araujo, M. D. A. (2020). The COVID-19 Pandemic and Climate Change: Why Have Responses Been So Different? E-International Relations. https://www.e-ir.info/2020/04/20/covid-19-pandemic-and-climate-change-why-have responsesbeen-so-different/\#google_vignette

Mooallem, J. (2013). Wild ones: A sometimes dismaying, weirdly reassuring story about looking at people looking at animals in America. New York, NY: Penguin Books.

Monroe et al., "Identifying Effective Climate Change Education Strategies."

Myers et al., "Public Health Frame." 
Nieman Lab. If you're not a climate reporter yet, you will be: Covid-19 coverage offers lessons for reporting on the climate crisis. (n.d.). Nieman Lab. https://www.niemanlab.org/2021/07/if-youre not-a-climatereporter-yet-you-will-be-covid-19-coverage-offers-lessons-for-reporting-on-the climate-crisis/

O’Neill, S. J., \& Nicholson-Cole, S. (2009). "Fear won't do it" promoting positive engagement with climate change through visual and iconic representations. Science Communication, 30(3), 355-379.

Renee N. Salas MD, MPH, MS, R. N. S. (2020). 2020 Lancet Countdown on Health and Climate Change: U.S. Policy Report. Harvard T.H. Chan School of Public Health.

https://www.hsph.harvard.edu/c-change/news/2020lancetcountdown/

Sarah Moore, S. M. (2021). Climate Change and COVID-19. News Medical. https://www.news medical.net/health/Climate-Change-and-COVID-19.aspx

Slocum, R. (2004). Polar bears and energy-efficient lightbulbs: Strategies to bring climate change home. Environment and Planning D: Society and Space, 22(3), 413-438. doi:10.1068/d378

Stenport, A. W., \& Vachula, R. S. (2017). Polar bears and ice: Cultural connotations of Arctic environments that contradict the science of climate change. Media, Culture \& Society, 39(2), 282295. doi:10.1177/0163443716655985

Swim, J. K., \& Bloodhart, B. (2015). Portraying the perils to polar bears: The role of empathic and objective perspectivetaking toward animals in climate change communication. Environmental Communication, 9(4), 446-468. doi:10.1080/17524032.2014.987304

Tori DeAngelis, T. D. A. (2020). Could COVID-19 change our environmental behaviors? American Psychological Association. https://www.apa.org/monitor/2020/07/environmentalbehaviors 